\title{
Acute prurigo simplex in humans caused by pigeon lice ${ }^{*}$
}

\author{
Hamilton Ometto Stolf ${ }^{1}$ \\ Ana Cláudia Cavalcante Espósito ${ }^{3}$
}

\author{
Rejane d'Ávila Reis² \\ Vidal Haddad Júnior ${ }^{3}$
}

DOI: http://dx.doi.org/10.1590/abd1806-4841.20187120

\begin{abstract}
Pigeon lice are insects that feed on feathers of these birds; their life cycle includes egg, nymph and adult and they may cause dermatoses in humans. Four persons of the same family, living in an urban area, presented with widespread intensely pruritic erythematous papules. A great number of lice were seen in their house, which moved from a nest of pigeons located on the condenser of the air-conditioning to the dormitory of one of the patients. Even in urban environments, dermatitis caused by parasites of birds is a possibility in cases of acute prurigo simplex. Pigeon lice are possible etiological agents of this kind of skin eruption, although they are often neglected, even by dermatologists.
\end{abstract}

Keywords: Anoplura; Ectoparasitic infestations; Lice infestations; Mites; Mite infestations; Phthiraptera; Prurigo

\section{INTRODUCTION}

Gamasoidosis, described with an increased frequency in the dermatology practice, is a dermatozoonosis caused by mites, particularly the species Dermanyssus gallinae. ${ }^{1,2}$ This arthropod is an avian parasite known by many common names such as poultry red mite, chicken mite and roost mite. It is a universal small insect, measuring around $1 \mathrm{~mm}$ in diameter. It can parasite many birds, including urban pigeons and caged birds, and is responsible for the most common dermatosis caused by bird parasites in our community. ${ }^{1,2}$ However, other dermatoses can be caused by bird arthropods. Lice, that are insects from the Anoplura and Mallophaga orders, can also cause short-lived dermatites in humans. Bird lice measure up to $10 \mathrm{~mm}$ in diameter, have three pairs of legs and a flat body, and can infest residences because of pigeon nests in certain areas, such as the ceiling lining or air-conditioner devices. ${ }^{3-5}$

Pigeon lice are chewing insects and do not bite as human lice, feeding on feathers and fur (melophagus = eater of fur), even though some species can feed on the blood from the bite injuries. ${ }^{3-5}$ They do not have wings and have similar life cycles to human scalp lice, with nymphs and adults living in the same parasitic area. The eggs are also stuck to the fur and feathers, such as scalp and human body lice (Pediculus humanus) nits and pubic lice (Phthirus pubis).
We report four florid cases of a household infestation of pigeon lice, whose reports in the literature are not common compared to the cases of gamasoidosis. Many times, some dermatologists are unaware of the differences between both conditions.

\section{CASES REPORT}

It is a household outbreak involving four people of the city of Campinas, state of São Paulo. The patients lived in an urban area, in a residential neighborhood.

The index patient was a male, 10-year-old child, student, with the complaint of widespread intensely pruritic erythematous papules on the body. They first appeared on the forearms and progressively increased in number, also appearing on the chest, shoulders and lower limbs (Figures 1 and 2). The other patients were three adults: a 60 -year-old male, with pruritic papules on the upper limbs; and two women, a 45-year-old and a 52-year-old with a smaller number of similar lesions on the axillae and lateral chest (Figure 3). The intense pruritus of the lesions was remarkable.

In the house, we noticed the lice moving through the window into the child's bedroom from a pigeon nest localized on the condenser of the air-conditioner, infesting the mattress and small

Received on 28.03.2017.

Approved by the Advisory Board and accepted for publication on 23.06.2017.

Study conducted at the Department of Dermatology and Radiotherapy, Faculdade de Medicina de Botucatu, Universidade Estadual Paulista "Júlio de Mesquita Filho" (FMB-Unesp) - Botucatu (SP), Brazil.

Financial support: None.

Conflict of interest: None.

Discipline of Dermatology, Faculdade de Ciências Médicas, Universidade de Campinas (FCM-Unicamp) - Campinas (SP), Brazil.

Private practice - Campinas (SP), Brazil.

Department of Dermatology and Radiotherapy, Faculdade de Medicina de Botucatu, Universidade Estadual Paulista "Júlio de Mesquita Filho" (FMB-Unesp) - Botucatu (SP), Brazil.

\section{MAILING AdDRESS:}

Vidal Haddad Jr.

E-mail: haddadjr@fmb.unesp.br

(C)2018 by Anais Brasileiros de Dermatologia 


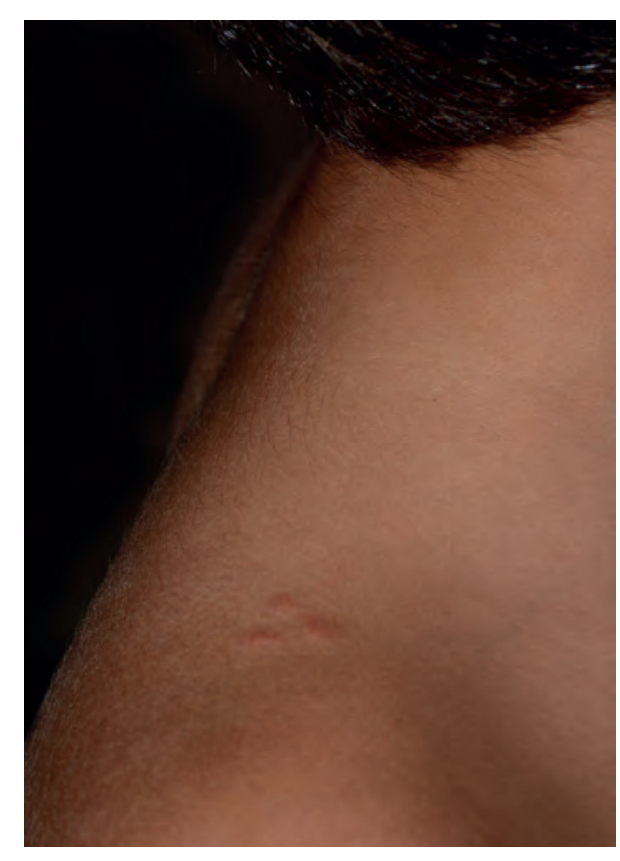

Figure 1:

Erythematous papules on the right shoulder of a 10-year-old child

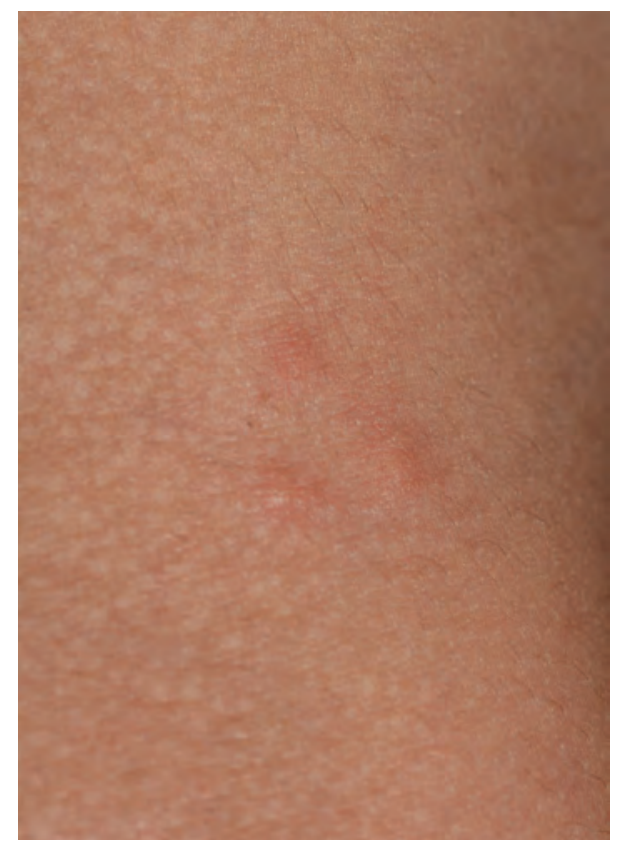

FIGURE 2:

Close-up view: grouped erythematous papules on the right shoulder of the index patient

cracks in the window and the room, attacking the humans at night in their search for food. The mother said she found the parasites on the bed sheets and mattress. The infestation took place mainly after the removal of the nest. Hundreds of leftover lice that were on the air-conditioner invaded the residence and tried to be parasitic to the dwellers. In figures 4 to 6 , we can see hundreds of lice moving laterally to the air-conditioner.

The patients were medicated with steroid creams and hygienic measures inside the residence, such as washing of all the bed

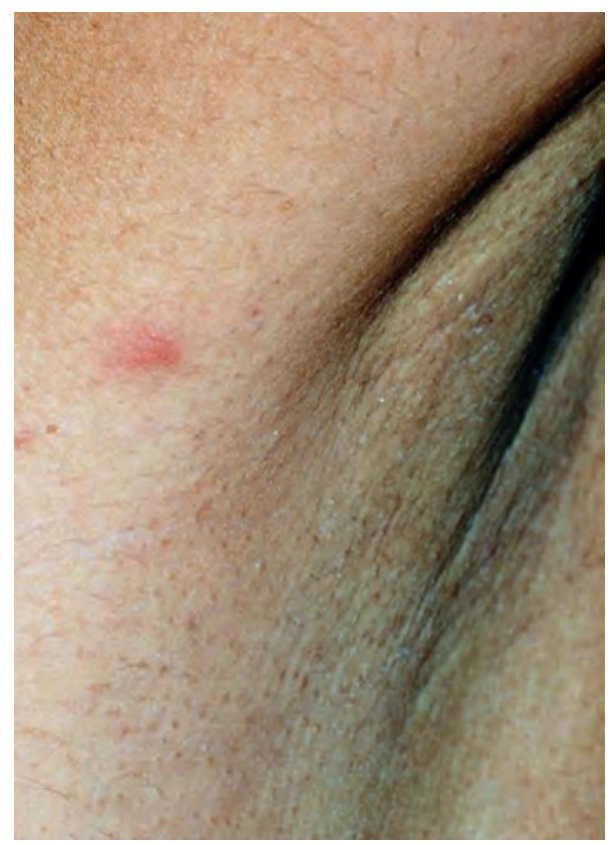

Figure 3:

Erythematous papule on the right axilla of one of the adult women

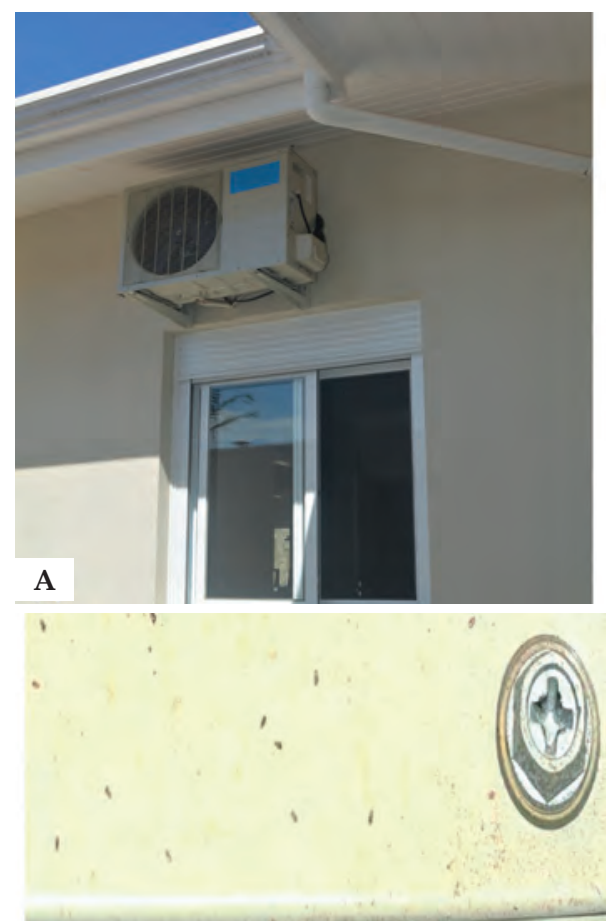

Figure 4: A Air-conditioner condenser: previous area of the pigeon nest. B - Close up of the side of the air-conditioner, where we can visualize the pigeon lice 


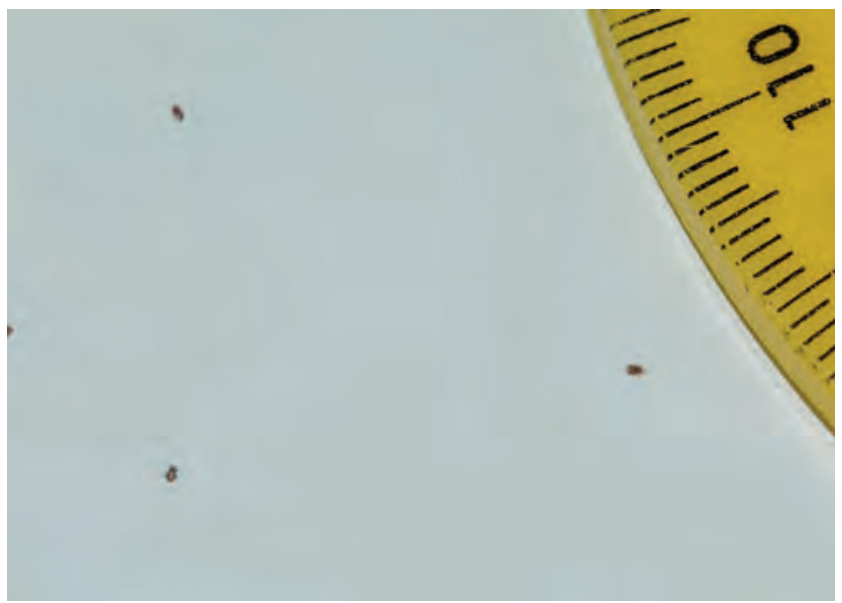

Figure 5: Multiple pigeon lice found inside the bedroom of the index patient

sheets and clothes in the bedrooms, besides a thorough cleaning of the air-conditioner and fumigation of the residence and the area where the pigeon nest was removed from. As repellent, inert polymer gel was used over the air-conditioner where the birds used to land, which was very effective in preventing the return of the birds. Even using the topical medication as prescribed, it took two weeks for the complete resolution of the lesions.

\section{DISCUSSION}

Pigeon lice that can cause dermatitis in humans belong to the species Mallophaga columbicola and Columbicola columbae. Although they usually do not attack humans, in some conditions with animals infested with large number of parasites in the houses, the lice end up in the rooms looking for shelter in cracks in the walls, folded fabrics and other hiding places. Since they need to feed, they can "chew" on human skin (with a usually unsuccessful feeding) and cause self-limited but intensely pruritic dermatoses.

Pigeon lice bites cause a papular pruritic dermatitis, with an irregular relief due to the bites, sometimes with vesicles and bul-

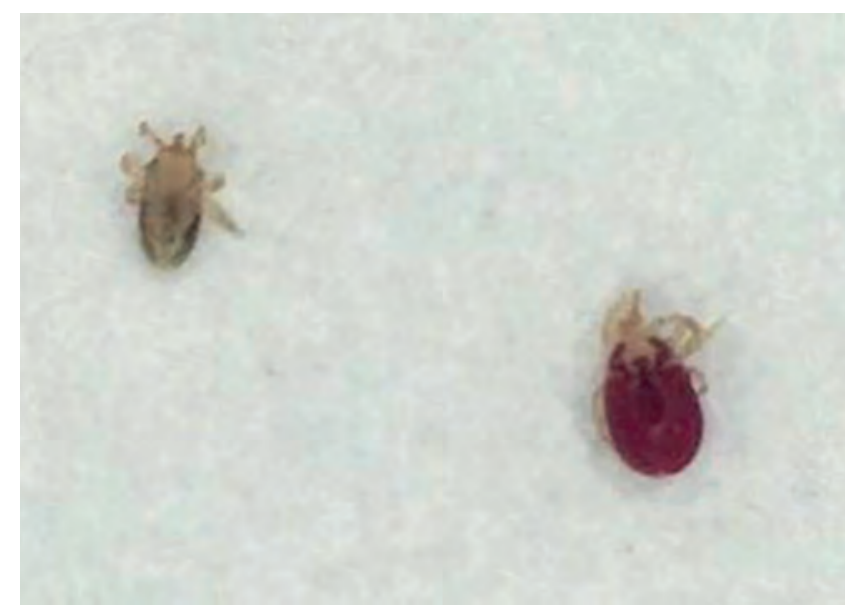

Figure 6: Adult pigeon lice: three pairs of legs and flat body (X10 magnification)

lae in sensitized individuals. Little is known about the substances that cause sensitization. Lesions are seen in a small number, but in highly infested residences the number of lesions in one individual can be large, such as in this report. Treatment is done with systemic antihistamines and topical corticosteroids, and one must watch for possible secondary infection due to scratching. Prevention demands removal of pigeons from inhabited areas and thorough cleaning of these places.

The four reported cases have 2 curious features. The first one is realizing that not all lesions by bird parasites are caused by the same agents, even though the clinical aspects are the same. When we think of occasional human parasitism caused by bird parasites, we immediately associate it to the mites that cause gamasoidosis. However, insects such as pigeon lice, can also cause short-lived acute pruritus. The second relevant feature is to always consider the possibility of parasites from birds in cases of acute prurigo simplex (even in urban environment), because they are associated to the presence of pigeons, common birds in any urban environment nowadays. $\square$

\section{REFERENCES}

1. Wambier CG, Wambier SP. Gamasoidosis illustrated - From nest to dermoscopy. An Bras Dermatol. 2012;87:926-7.

2. Suzuki CMP, Stolf HO, Camargo RMP, Haddad Jr V. Gamasoidose ou dermatite por ácaros aviários: relato de caso. Diagn Tratamento. 2014;19:74-6.

3. Ash J. A Study of the Mallophaga of Birds with Particular Reference to their Ecology. Ibis. 1960;102:93-110.
4. Bush SE, Sohn E, Clayton DH. Ecomorphology of parasite attachment: Experiments with feather lice. J Parasitol. 2006;92:25-31.

5. Higieneatual.blogspot [Internet]. Higiene Atual. Sobre os piolhos de pombos [acesso 24 fev 2017]. Disponível em: http://higieneatual.blogspot.com. br/2013/07/sobre-os-piolhos-de-pombos.html

How to cite this article: Stolf HO, Reis RD, Espósito ACC, Haddad Jr V. Acute prurigo simplex in humans caused by pigeon lices. An Bras Dermatol. 2018;93(2):285-7. 